\title{
Stability Evaluation of a Quay Wall of Large Cylinders
}

\author{
Jian-Min Zhang, Jianhong Zhang ${ }^{*}$, Gang Wang and Yang Chen
}

State Key Laboratory of Hydroscience and Engineering, Tsinghua University Beijing, 100084, China

\begin{abstract}
The stability of the quay wall incorporating large diameter cylinders is of great concern at the Yangshan Port, China, owing to severe marine environment. In this study, finite element analysis is carried out to evaluate the stability of a trial quay wall during construction. The single cylinder is examined in terms of turnover failure subjected to a five year design wave action. The case when the cylinder is empty is the critical situation during construction. Filling the cylinder right after the installation is an effective way to increase the stability. After the quay wall has been formed by joining the single cylinders, the safety against overturning is reevaluated. The factor of safety of the quay wall is assessed to be 1.5 under a fifty year design wave action.
\end{abstract}

Keywords: Finite element method, large diameter cylinder, stability.

\section{INTRODUCTION}

The continuing demand for transportation and water management in China has stimulated an enormous investment in coastal engineering. Shanghai Port (Fig. 1) has gained its leading position in shipping in China in terms of its 25 container berths and thus a volume of freight moving of $6,450,000$ containers each year. This has been obviously the result of China's re-entrance to the world market, and of the economic growth and development in the region. However, the port facilities are far from sufficient to accommodate the rapid increasing demand for container handling services. Moreover, water depth of the channel at the estuary of the Yangtze River is only $8.5 \mathrm{~m}$. The shallowness of the port confines it to small container ships. It initiated the design and construction of new port near Shanghai to meet the changes of the new container era.

The Yangshan Port is located on the archipelago of Hangzhou Bay at the estuary of the Yangtze River, as shown in Fig. (1), only 45 miles to the international sea route. It is also the nearest port to Shanghai, naturally formed with sound geographical location and a water depth of $15 \mathrm{~m}$. Five container berths were put into use after the Phase I project was implemented in 2005. In order to provide efficient links to foreign markets and enhance the competence of Chinese economy, Yangshan Port will be further developed to take the advantage of the vital juncture of the booming Yangtze region. Advanced technology, novel design concept are essential to ensure a reliable design of quay walls for the port and to meet the requirement for large-scale shipment currently used in the international market.

Foundations of large diameter cylinder have successful applications in coastal and offshore engineering [1-4] (Zhang et al. 2007, 2008). Shallow-embedded steel cylinder was first developed in Japan. Single cylinders are joined together

* Address correspondence to this author at State Key Laboratory of Hydroscience and Engineering, Tsinghua University, Beijing, 100084, China; Tel: 86-10-62792984; Fax: 86-10-62785593; Email: cezhangjh@tsinghua.edu.cn

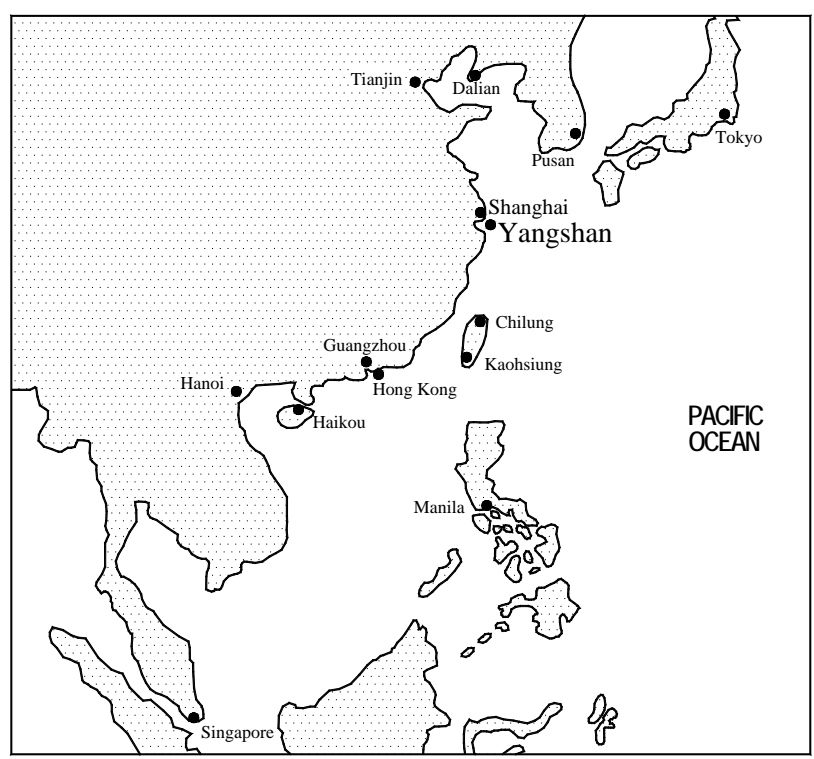

Fig. (1). Ports in East and South east region.

by gridirons to form a quay wall. This cylinder was recommended to be used at the Yangshan Port. For a preliminary feasibility study, a trial quay wall of $400 \mathrm{~m}$ in length was implemented at the site prior to construction of the actual wall. The purpose of the field investigations was to examine the performance of the structure when exposed to wave action.

This paper presents a safety evaluation of the trial quay wall with large diameter cylinders at the Yangshan Port based on finite element method. A five year design wave action is incorporated to investigate the instability of the single cylinder during construction. After the quay wall is completed by joining the single cylinders, the safety against overturning is evaluated under a fifty year design wave action. The factor of safety of the quay wall was given during operation period. 


\section{LOADING CONDITIONS}

Typical cross section and geological conditions of the quay wall are shown in Fig. (2). There is a layer of very soft organic sediment with varying thickness across the site, extending from the seabed up to $2.8 \mathrm{~m}$ depth. The foundation soils are generally composed of weak sediments such as layered fine sand, silt and silty clay. The diameter of the cylinder is $22.0 \mathrm{~m}$, made of steel plate with a thickness of $18 \mathrm{~mm}$. The maximum height of the cylinder is $22.5 \mathrm{~m}$. Elevations of the sea bed range between $-8.5 \mathrm{~m} \sim-10.2 \mathrm{~m}$. Embedment depths of the cylinder range between $4 \sim 7.8 \mathrm{~m}$.

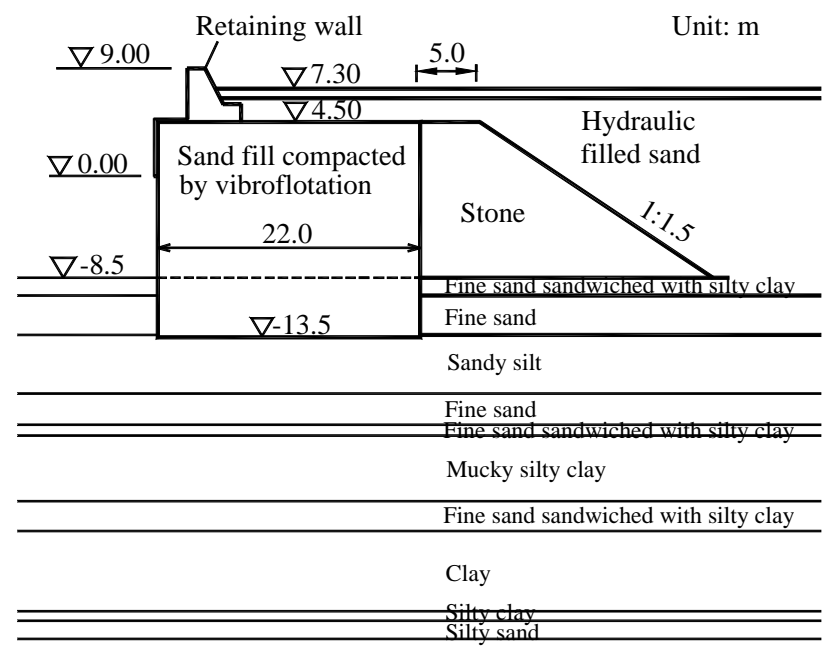

Fig. (2). Cross section of large diameter cylinder.

Schematic diagram of loading conditions of the cylinder during construction are illustrated in Fig. (3). With regard to single cylinder, pressures induced by the wave action and difference of still water level are the two main loads considered and applied on the foreshore side of the cylinder. Flow around a single cylinder occurs when it is in construction. However, it will not happen in case when the quay wall is completed. The differences of still water level between the foreshore and inshore side of the quay wall induced by rapidly rising tides will impose water pressures on the quay wall.

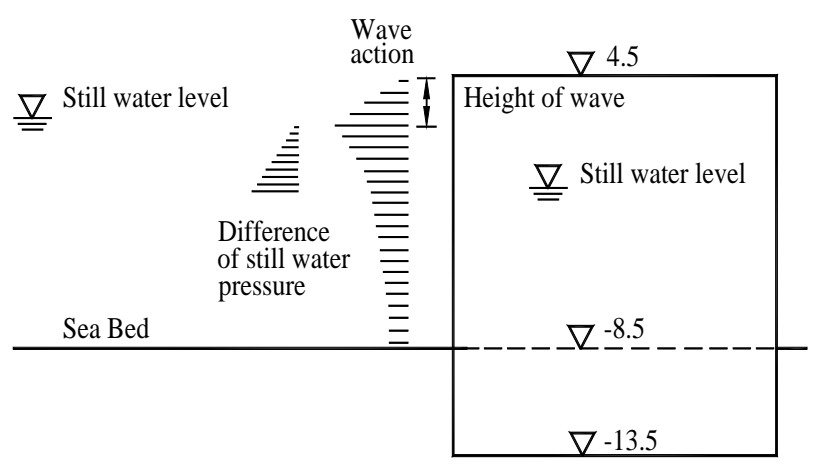

Fig. (3). Loading conditions of the cylinder.

\section{CONSTRUCTION PROCEDURES}

The construction procedures for the cylinder are as follows: The steel cylinder is driven down by a vibrating ham- mer. After reaching a prescribed tip elevation, the cylinder is immediately filled with sand which will then be compacted by vibroflotation technique. Single cylinders are joined by gridiron to form a quay wall. The quay wall is backfilled with soils at the inshore side. In terms of the characteristics of the construction, the stability analysis has six aspects:

(1) Stability of the single cylinder during dynamic installation;

(2) Stability of the empty single cylinder before sand filling, subjected to wave action;

(3) Bearing capacity of the foundation beneath the cylinder during sand filling;

(4) Stability against overturning of the single cylinder subjected to 5 year design wave action;

(5) Stability against overturning of the quay wall formed by connecting single cylinders subjected to 50 year design wave action;

(6) Deformation and stability of the quay wall during the back fill of the soils.

The first two aspects belong to the stability of shell structures under static and dynamic loads. The third and sixth aspects, associated with bearing capacity and deformation of foundation, will be discussed in detail in another paper concerning jetties for channel protection at Huanghua Port [4]. This paper only presents study associated with the fourth and fifth aspects, i.e. the safety assessment of the single and quay wall subjected to the design wave actions.

\section{FINITE ELEMENT ANALYSIS}

Finite element analysis associated with the cylinderfoundation system subjected to wave action is carried out using DIANA-SWANDYNE II [5-7]. The cylinder and the foundation soils are assumed to be rigid and elasto-plastic materials, respectively. The elastic modulus of the soils is estimated in terms of the constrained modulus which is available in the report of geological survey [8] (Internal report of Department of Hydraulic Engineering 2004). MohrCoulomb principle is set as the failure criterion for the soils. A rapid filling of the single cylinder as well as an immediate wave loading have been considered. The soil is assumed undrained as the non-equilibrium pore water pressures in the soil were difficult to predict. The shear strength parameters for the soils were obtained from direct shear test on consolidated samples under rapid shearing. Table 1 shows the parameters of the soils.

Five year design wave action is adopted for the single cylinder under construction, while fifty year design wave action is applied for the quay wall when the single cylinders have been joined together. Forces imposed on the cylinder are derived from the design wave action. Although the wave loads are of a dynamic nature, the analysis presented here is a quasi-static one. In terms of the Code of Hydrology for Sea Harbor JTJ213-98 [9], the pressure of waves and currents breaking on the cylinder can be regarded as a distributed load, as shown in Fig. (3). The distribution pattern is assumed identical regardless of the time. However, the magnitude of the load will vary linearly. The factor used to describe the load intensity is written as 
Table 1. Parameters of Materials

\begin{tabular}{|c|c|c|c|c|c|}
\hline Material & $\begin{array}{c}\text { Young's } \\
\text { Modulus } \\
\text { (MPa) }\end{array}$ & $\begin{array}{c}\text { Poisson } \\
\text { Ratio }\end{array}$ & $\begin{array}{c}\text { Saturated } \\
\text { Unit Mweight } \\
\left(\mathbf{N} / \mathbf{m}^{3}\right)\end{array}$ & $\begin{array}{l}\text { Consolidated Undrained } \\
\text { Cohesion } c_{c u}(\mathbf{k P a})\end{array}$ & $\begin{array}{c}\text { Consolidated } \\
\text { Undrained Friction } \\
\text { Angle } \\
\phi_{c u}{ }^{\circ}\end{array}$ \\
\hline $\begin{array}{c}\text { Fine sand } \\
\text { sandwiched } \\
\text { with silty clay }\end{array}$ & 6.48 & 0.35 & 18900 & 8.90 & 30.30 \\
\hline Fine sand & 7.06 & 0.32 & 19100 & 3.00 & 33.50 \\
\hline Sandy silt & 7.66 & 0.35 & 19100 & 5.50 & 33.00 \\
\hline Silty clay & 1.79 & 0.36 & 18100 & 15.00 & 20.00 \\
\hline $\begin{array}{c}\text { Silty clay } \\
\text { sandwiched } \\
\text { with fine sand }\end{array}$ & 2.68 & 0.36 & 18600 & 13.00 & 23.00 \\
\hline Clay & 8.25 & 0.32 & 19800 & 73.50 & 19.70 \\
\hline Silty sand & 6.50 & 0.32 & 19200 & 2.50 & 34.00 \\
\hline muck & 1.01 & 0.36 & 16400 & 8.50 & 13.50 \\
\hline Backfill sand & 8.0 & 0.3 & 19500 & & \\
\hline Steel & $2.06 \mathrm{E} 5$ & 0.2 & 78500 & & \\
\hline
\end{tabular}

$\alpha_{\mathrm{p}}=\frac{p(z, \theta)}{p_{\mathrm{o}}(z, \theta)}$

where $p_{0}(z, \theta)$ is the design wave load applied on the structures, which is a distributed load; $z$ is the vertical coordination of the cylinder; $\theta$ is the radial coordination of the cylinder, which is the angle between the wave ray and a line connecting the calculating point and the center of the cylinder. $p(z, \theta)$ is the term in relation to the load and displacement, having the same distribution pattern with $p_{0}(z, \theta)$ and being evaluated by the factor of $\alpha_{p}$.

According to current practice, the cylinder is assumed to be subjected to the monotonic loading described by $p(z, \theta)$, which is considered to approximately represent actual loading conditions. The relationship between the load and the displacement of the cylinder, $p(z, \theta)$, will be assessed through the finite element analysis so as to determine the ultimate bearing capacity of the cylinder by identifying the upper limit load $p_{u}(z, \theta)$ on the load-displacement curve.

The factor of safety $F$ against overturning of the cylinder or the quay wall is defined as the ratio of the ultimate load $p_{u}(z, \theta)$ which brings the structure to failure to the design wave load $p_{0}(z, \theta)$.

$F=\frac{p_{\mathrm{u}}(z, \theta)}{p_{\mathrm{o}}(z, \theta)}$

Referring to Eq. (1), Eq. (2) can be rewritten as

$F=\alpha_{\mathrm{p}, \mathrm{u}}$
The factor of safety of the cylinder against overturning is the limit value of the load intensity, i.e. $\alpha_{p, u}$.

\section{STABILITY OF SINGLE CYLINDER}

Features of the five year design wave are illustrated in Table 2. The single cylinder subjected to the wave action is a three dimensional problem. However, from a viewpoint of the wave direction, it then can be subsequently simplified to be a plane symmetrical problem. Therefore, a half cylinder and foundation are considered, and solid elements of 20node hexahedron are used to discretize the concerned region, as shown in Fig. (4). Friction contact elements are set between the cylinder and the soils.

Table 2. Features of Five Year Design Wave

\begin{tabular}{|c|c|c|c|c|}
\hline $\begin{array}{c}\text { Wave } \\
\text { Height } \\
(\mathbf{m})\end{array}$ & $\begin{array}{c}\text { Speed } \\
(\mathbf{m} / \mathbf{s})\end{array}$ & $\begin{array}{c}\text { Wave } \\
\text { Length } \\
(\mathbf{m})\end{array}$ & $\begin{array}{c}\text { Period } \\
(\mathbf{s})\end{array}$ & $\begin{array}{c}\text { Still Water } \\
\text { Depth } \\
(\mathbf{m})\end{array}$ \\
\hline \hline 4.24 & 2.0 & 47.0 & 5.6 & +4.51 \\
\hline
\end{tabular}

The stability analysis of the single cylinder has to consider following situations: (1) Empty cylinder with no sand fill; (2) Half filled Cylinder; (3) Fully filled cylinder. In terms of the design wave action as shown in Table 2 , the resultant forces of are calculated to be $1970 \mathrm{kN}$ and $5550 \mathrm{kN}$ at wave heights of $1.5 \mathrm{~m}$ and $4.24 \mathrm{~m}$, respectively. The resultant force imposed by the current is $228 \mathrm{kN}$ at a current speed of $2 \mathrm{~m} / \mathrm{s}$. 
With parameters for various materials in Table $\mathbf{1}$, the estimated deformation of the cylinder under the wave action is shown in Fig. (5). A turnover failure of the cylinder is indicated to be susceptible. The curves of inclination versus wave load are depicted in Fig. (6). As seen in Fig. (6), the inclination angle of the cylinder is increased associated with the load. When the load reaches a certain value, the inclination angle will be increased rapidly especially for the empty cylinder, indicating instability of the cylinder. The curves present an upper limit for the load where the cylinder is failed, which will then be used in the estimation of the factors of safety.

The factors of safety against overturning are assessed in terms of Eqs. (2) and (3). The results are listed in Table 3 for the empty cylinder, the cylinder half filled with sand or fully filled with sand. As seen in Table $\mathbf{3}$, the cylinder in empty is the critical situation, exhibiting the lowest factor of safety of 1.2. The factors of safety for the cylinder half filled with sand and fully filled with sand are 1.9 and 2.4, respectively. Therefore, filling the cylinder with sand, in consequence, can effectively enhance the stability of the cylinder thus reduce the potential of overturning failure.

Table 3. Factor of Safety of Single Cylinder

\begin{tabular}{|c|c|}
\hline State of Cylinder & Factor of Safety \\
\hline \hline Empty & 1.2 \\
\hline Half filled with sand & 1.9 \\
\hline Full filled with sand & 2.4 \\
\hline
\end{tabular}

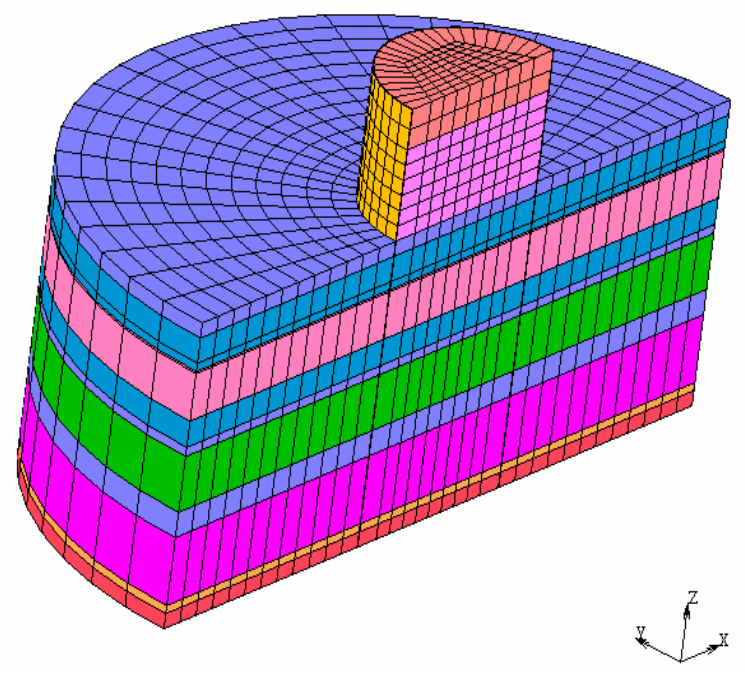

Fig. (4). Numerical model for single cylinder.

\section{STABILITY OF QUAY WALL}

The quay wall is formed by joining the single cylinders and is long enough to be regarded as a plane strain problem. Fig. (7) shows the two-dimensional element mesh for the quay wall. The parameters of the soils and the steel are referred to Table $\mathbf{1}$.

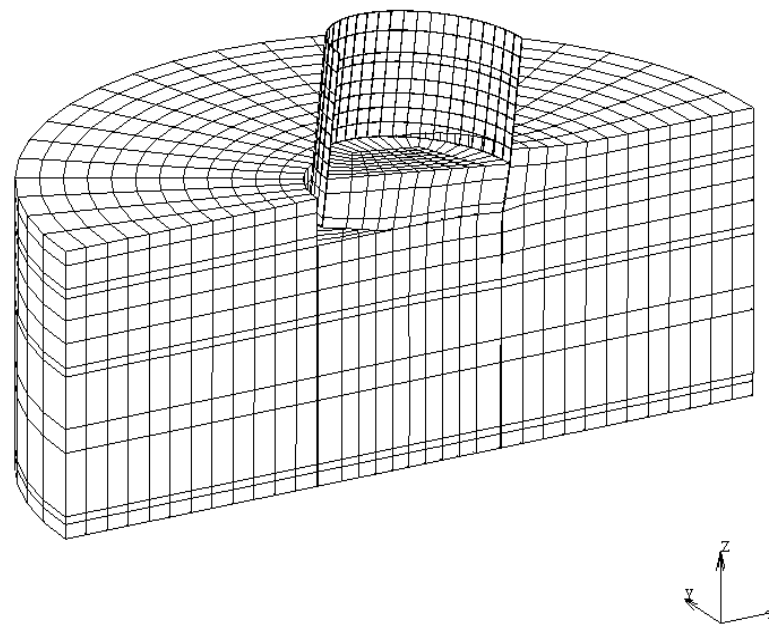

Fig. (5). Overturn of empty cylinder.

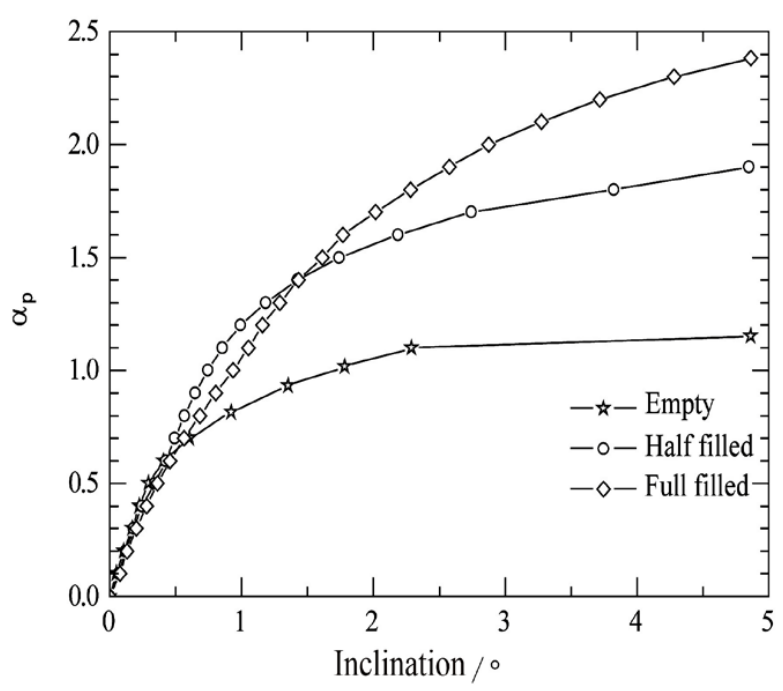

Fig. (6). Load versus inclination of single cylinder.

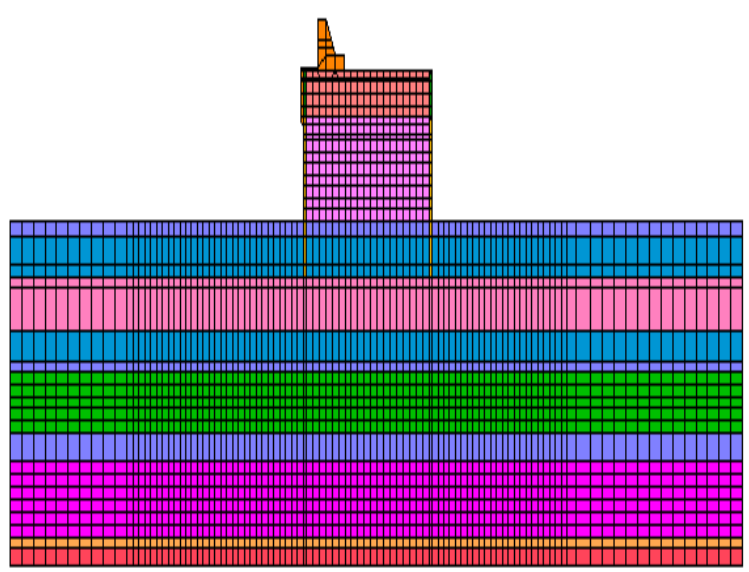

Fig. (7). Element mesh for the quay wall. 
Table 4. Features of Fifty Year Design Wave

\begin{tabular}{|c|c|c|c|c|}
\hline $\begin{array}{c}\text { Wave Height } \\
(\mathbf{m})\end{array}$ & $\begin{array}{c}\text { Wave length } \\
(\mathbf{m})\end{array}$ & $\begin{array}{c}\text { Period } \\
\text { (Second) }\end{array}$ & $\begin{array}{c}\text { Foreshore Still } \\
\text { Water Level } \\
(\mathbf{m})\end{array}$ & $\begin{array}{c}\text { Inshore Still } \\
\text { Water Level } \\
(\mathbf{m})\end{array}$ \\
\hline \hline 5.17 & 71.2 & 7.3 & +4.51 & +0.53 \\
\hline
\end{tabular}

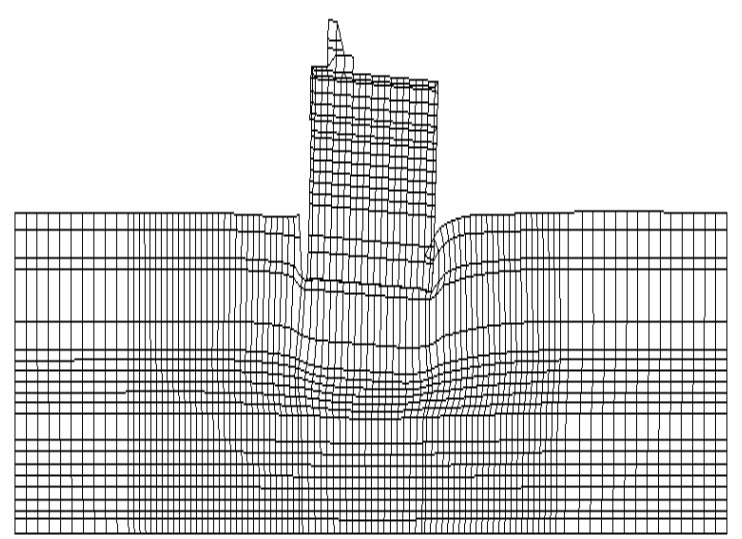

Fig. (8). Overturn of quay wall.

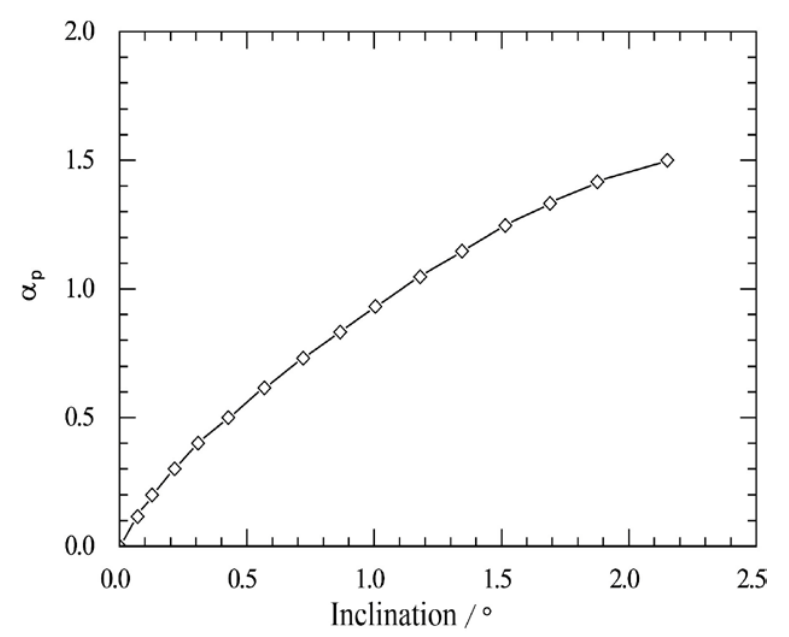

Fig. (9). Load versus inclination of quay wall.

Compared with the single cylinder, no flow around the cylinder occurs in case when the quay wall is completed. Therefore the force resulted from the current is not included in the analysis of the quay wall. However, differences of still water level between the foreshore and inshore side of the quay wall induced by rapidly rising tides will still impose water pressures on the quay wall. Wave action concerns a 50 year design wave load, with features listed in Table 4. The horizontal resultant forces imposed by wave action and difference of water level are $635.8 \mathrm{kN} / \mathrm{m}$ and $79 \mathrm{kN} / \mathrm{m}$, respectively. Owing to the low permeability of the foundation soils, excess pore water pressure induced by wave action is considered not to dissipate, which in consequence renders uplift pressure on the cylinder.
The deformation of the quay wall under wave action is shown in Fig. (8), presenting a similar movement mode as the single cylinder. However, owing to the integrity of the quay wall, the overall stability is increased. Therefore, the factor of safety of the quay wall against overturning is assessed to be 1.5 under a fifty year design wave. The curve of inclination versus wave load is depicted in Fig. (9). The inclination angle of the quay wall is nonlinearly increased associated with the load.

\section{CONCLUSIONS}

This paper presents a study with finite element method of a trial quay wall of large diameter cylinders at Yangshan Port. Through extensive analysis, following conclusion remarks can be drawn.

With a five year design wave action, the single cylinder during construction presents a potential of overturning failure. The cylinder in empty is the critical situation, with a factor of safety of 1.2. Filling the cylinder in time is very effective to increase the stability.

The quay wall formed by joining the cylinders together is reevaluated against overturning. The factor of safety of the quay wall is assessed to be 1.5 under a fifty year design wave action.

\section{ACKNOWLEDGEMENTS}

The research work was funded by the National Basic Research Program of China (2007CB714102) and National Natural Science Foundation of China (50679035).

\section{REFERENCES}

[1] X.B. Lu, S.Y. Wang, J.H. Zhang, G.L. Sun and Z.M. Shi, "Experimental study of pore pressure and deformation of suction bucket foundations under horizontal dynamic loading," China Ocean Engineering, vol. 19, pp. 671-680, August 2005.

[2] J.H. Zhang, L.M. Zhang and X.B. Lu, "Centrifuge modeling of suction bucket foundations for platforms under ice-sheet-induced cyclic lateral loadings," Ocean Engineering, vol. 34, pp. 10691079, June 2007.

[3] J.M. Zhang, J.H. Zhang, G. Wang and Y. Chen, "Stability of jetties for channel protection in soft soils at huanghua port," Ocean Engineering, vol. 35, pp. 1716-1726, December 2008.

[4] J.M. Zhang, J.H. Zhang, G. Wang and Y. Chen, "Safety evaluation of breakwaters based on physical and numerical modeling", Ocean Engineering, vol. 36, pp. 852-862, August 2009.

[5] A. Chan, User Manual for DIANA -SWANDYNE II - Dynamic Interaction And Nonlinear Analysis SWANsea DYNamic program version II, Department of Civil Engineering, University of Glasgow, 1993.

[6] M. Pastor, O. Zienkiewicz and A. Chan, "Generalized plasticity and the modeling of soil behavior", International Journal for $\mathrm{Nu}$ merical and Analytical Methods in Geomechanics, vol. 14, pp. 151190, 2005.

[7] O. Zienkiewicz and A. Chan, "Computational Geomechanics with Special Reference to Earthquake Engineering" John Wiley \& Sons: New York, 1998. 
[8] Geological survey, Internal report of Department of Hydraulic Engineering, Tsinghua University, Beijing, China, 2004.
[9] China communication first design institute of navigation engineering, Code of Hydrology for Sea Harbor JTJ213-98, China Communications Press, China, 1998.

Received: July 15, 2009

(c) Zhang et al.; Licensee Bentham Open.

This is an open access article licensed under the terms of the Creative Commons Attribution Non-Commercial License (http://creativecommons.org/licenses/by-nc/3.0/) which permits unrestricted, non-commercial use, distribution and reproduction in any medium, provided the work is properly cited. 